\title{
Review of studying on Fatigue Damage of Concrete Bridge
}

\author{
Lihui Yin ${ }^{1, a}$, Zonglin Wang ${ }^{2, b}$ \\ ${ }^{1}$ School of Transportation Science and Engineering, Harbin Institute of Technology, China \\ ${ }^{1}$ Institute of Architecture and Engineering, HeiLongJiang University, China \\ ${ }^{2}$ School of Transportation Science and Engineering, Harbin Institute of Technology, China \\ a yinlihui666@126.com, ${ }^{b}$ wangzonglin@vip.163.com
}

Keywords: concrete bridge; fatigue damage; repeated load

\begin{abstract}
In this paper, it systematically reviews the research status of fatigue damage of concrete bridges on the basis of previous studies and the problems for further research are discussed. From the bridge component materials perspective, the paper analyses the status and the development direction of the dynamic constitutive models. At the same time, the paper summarizes the fatigue cumulative damage theory and analyses the advantages and disadvantages of the various theories. The main contents of this paper include: the research history and status of fatigue damage of concrete bridges, the damage variable selection, the fatigue cumulative damage theory, the problems for further research on the fatigue damage of concrete bridge.
\end{abstract}

\section{Introduction}

In 1829, German engineer Albert studied the hoist hinge fatigue strength. From then on, people began to pay attention to the fatigue damage of metallic materials. In 19th century end, the fatigue characteristics of concrete materials began to be studied. In 1898, Considere and Dejoly launched an in-depeh study on the fatigue characteristics of the mortar and concrete, and it can be said that this is the beginning of concrete fatigue characteristic research. At the beginning of $20^{\text {th }}$ century, along with the development of highway, railroad and aviation industry in the word, people paid more and more attention to the research on the fatigue damage properties ${ }^{[1,2,3,4,5,6,7,8]}$.

Especially as the highway traffic infrastructure engineering, highway bridge plays a cruial role in highway transportation system. Under the action of various factors, the bridge will be vibrated in vertical, longitudinal, transverse. If the dynamic response is too large, it will cause the structural fatigue accumulation. Because the bridge materials used are not homogeneous and continuous, in fact, there are many tiny defects. Under cyclic load, these mocro-defects will gradually develop, combined injury. If these micro-defects are not effectively controlled, it is very likely to arouse the brittle fracture of materials and structures. It will lead to the operational performance of bridge and structural safety of recession. Early fatigue damage is often not easy to be detected, but the consequences could be disastrous.

\section{The research status of fatigue damage of concrete bridges}

In 1958, CDM was proposed by Kachanov. Subsequently, Rabotnov introduced the damage variable. Since nineteen eighties, damage mechanics theory in the field of concrete material behavior modeling has been widely applied. Fatigue is the decay process of the structure stress performance under the action of repeated load. The fatigue essence is the material fatigue damage 
accumulation process along with the increase in the number of fatigue loading. Correctly understanding the damage generated and accumulated in the process is very important, because it is the basis of building damage equation, analyzing fatigue damage process of the material and predicting the fatigue life.

\subsection{The damage variable selection}

Under fatigue load, the material properties will deteriorate. The physical quantity, used to describe the material mechanical property deterioration, is named as the damage variable.

In 1938 and 1955 , Kommers ${ }^{[9]}$ and Henry ${ }^{[10]}$ took the chang of fatigue limit as the measurement of damage.

In 1988, Lemaitre ${ }^{[11]}$ used the sectional area reduction as the damage index:

$$
\mathrm{D}=1-\mathrm{A}_{1} / \mathrm{A}
$$

In this formula, " $\mathrm{A}_{1}$ " is the sectional area after cracking, " $\mathrm{A}$ " is the sectional area before cracking.

In 1993, Miroslaw ${ }^{[12]}$ regarded the fatigue failure as the process of energy release based on the principle of conservation of energy. So he defined the energy dissipation as the damage variable:

\section{$\mathrm{D}=\mathrm{E} /$ Etot}

In this formula, "E $E_{\text {tot }}$ " is the the total energy dissipation capacity, " $E$ " is the dissipation of energy.

In 1996, Ravindra ${ }^{[13]}$ defined the Splitting tensile strength attenuation as the damage variable:

$$
\mathrm{D}=1-\sigma_{\mathrm{t}} / \mathrm{f}_{\mathrm{t}}
$$

In this formula, " $\sigma_{t}$ " is the residual splitting tensile strength, " $\mathrm{f}_{\mathrm{t}}$ " is the initial split tensile strength.

\subsection{The fatigue cumulative damage theory}

The reasonable damage accumulation model is the basis of describing cumulative damage development process of structures or members under cyclic loading.

2.2.1 Linear cumulative damage theory

Linear cumulative damage theory ${ }^{[14]}$ is that "the relationship between fatigue damage and load cycling is linear under cyclic load. The fatigue damage can accumulate linearly. All stress is independent and unrelated. When the accumulated damage reaches a certain value, specimens or components will induce fatigue failure.

$$
\mathrm{D}=\mathrm{n} / \mathrm{N}
$$

In this formula, " $\mathrm{n}$ " is the stress cycle and " $\mathrm{N}$ " is the fatigue life of material. When the structure is destroyed, $\mathrm{D}=1$.

Because of its simple features, it has been widely used in engineering. But there are insufficient in miner theory, such as damage independent of the load status and cumulative damage independent of the load order.

\subsubsection{Nonlinear cumulative damage theory}

Many experiments showed that Fatigue cumulative damage law presented the characteristics of the nonlinear damage. Therefore the domestic and foreign scholars proposed a nonlinear fatigue damage cumulative model ${ }^{[15,16,17,18,19,20,21,22]}$.

The model of Freudenthal-Heller considered the interaction effect between loads, so it is more widely used in engineering. 


$$
D=n m^{c} r^{d}
$$

In this formula, " $n$ " is the stress cycle, " $m$ " is the material injury nuclear number, " $r$ " is the damage evolution rate, "c" and " $\mathrm{d}$ " are the material constant. When the structure is destroyed, $\mathrm{D}=\mathrm{N}_{1} \mathrm{~m}_{1}{ }^{\mathrm{c}} \mathrm{r}^{\mathrm{d}}$.

\section{The main problems of research of fatigue cumulative damage theory}

Because of the complexity of concrete structure, the existing research results also exist the following problems:

(1) Fatigue load on bridge structure fatigue research is very important, but our country has not stipulated relevant specification. Most researchers use the vehicle load spectrum as the fatigue load, rather than the form of standard fatigue vehicle, which causes the research of the vehicle bridge coupling vibration great difficulty.

(2) Most damage model is built on the common concrete structure, but most of the current concrete bridge structures use the high strength concrete. Using common concrete dynamic damage model to simulate fatigue damage behavior of high strength concrete is obviously not suitable.

(3) At present, most of the research has focused on the fatigue damage of earthquake. They have the important theory value for the structure under earthquake effect on fatigue damage. Most damage models give the definition of structural damage in macroscopical angle, but most of the existing models don't measure structure damage scales from the material deterioration scale.

(4) Most damage model rarely considered the bonding performance degradation law between steel bar and concrete in material level. In fact, the cause of actual bridge structure damage may be damaged in the joint surface between the reinforcement and concrete.

\section{Conclusions}

For concrete bridge, moving vehicle load is the main form of load. In order to better study the fatigue damage, firstly, we must study the standard form of fatigue load the vehicle. Secondly, we must study the material fatigue damage constitutive model. Finally, based on the vehicle bridge coupling vibration, we can study the mechanism of fatigue damage of concrete bridge.

\section{References:}

[1] Considere.M, Influence des armatures metalligues les proprietes des mortiera et betons, Compt Rendu de 1' academie Des Sciences.127(1898)992-995.

[2] Van O.J.L, Fatigue of concrete, Transactions, ASCE. 58(1907)294-320.

[3] Graf O., Brenner, Experiments for investigating the resistance of concrete under often repeated compression loads, Bulletin, Deutscher Ausschuss fur Stahlbeton. 83(1936)45-53.

[4] Clemmer H. E., Fatigue of concrete, Proceedings, ASTM. 22(1922)408-419.

[5] D. J. Cook and P. Chindaprasirt, Influence of loading history upon the tensile properties of concrete, Magazine of Concrete Research.116(1981)154-160.

[6] Traina L A., Jeragh A.A., Fatigue of plain concrete subjected to biaxial cyclical loading, ACI Publication.75(1982)154-160. 
[7] Eric C.M.Su, Thomas T.C.Hsu, Biaxial Compression fatigue and discontinuity of concrete, ACI Materials Journal. 3(1988)178-188.

[8] Kolluru V. Subramaniam, Fatigue of concrete subjected to biaxial loading in the tension region, $\mathrm{Ph}$. D. Dissertation, Northwestern University.12(1999)20-32.

[9] Kommers J B, The effect of overstressing and understressing in fatigue, Amerrica Socoiety Testing and Materials. 38(1938)249-268.

[10] Henry D L, A theory of fatigue damage accumulation in steel, Transation of the ASME. 77(1955)913-918.

[11] Lemaitre J, A Continuous Damage Mechanics Model for Ductile Fracture, ASEM, Journal of Engineering Materials and Technology. 3(1988)83-89.

[12] Miroslaw Grzybowski, Christian Meyer, Damage accumulation in concrete with and without fiber reinforcement, ACI Materials Journal.6(1999)594-604.

[13] Ravindra Gettu, Antonio Aguado, Marcel 0.F.0liveira, Damage in high-strength concrete due to monotonic and cyclic compression-a study based on splitting tensile strength, ACI Materials Journal. 6(1996)519-523.

[14] Miner M A, Cumulative damage in fatigue, J Appl Mech. 12(1945)159-164.

[15] Marco S M, Starkey W L, A concept of fatigue damage, Transaction of the ASME, 75 (1954) 627-632.

[16] Manson S S, Halford G R. Practical implementation of the double linear damage rule and damage curve approach for treating cumulative fatigue damage, Int J.Fract.2(1981)169-192.

[17] Freudenthal A M, Heller R A, On stress interaction in fatigue and cumulative damage rule, Journal of the Aerospace Science.7(1959)431-442.

[18] Halford G R, The energy required for fatigue, Journal of Materials.1(1966)3-8.

[19] Niu X, Li G X, Lee H, Hardening law and fatigue damage of a cyclic hardening metal, Engineering Fracture Mechanics.2(1987)163-170.

[20] Chaboche J L, Lesene P M, A non-linear continuous fatigue damage model, Fatigue and Fracture of Engineering Materials and Structures.1(1988)1-7.

[21] Freudenthal A M, Heller R A, On stress interaction in fatigue and cumulative damage rule, Journal of the Aerospace Science.7(1959)431-442. 